\title{
Introducing Simulation Based Learning Activities to Physiotherapy Course Curricula
}

\author{
Diane M. Dennis*, David A. Sainsbury, Tracy M. Redwood, Leo Ng, Anne Furness \\ School of Physiotherapy and Exercise Science, Curtin University, Perth, Australia \\ Email: "D.Dennis@curtin.edu.au
}

Received 21 April 2016; accepted 14 May 2016; published 17 May 2016

Copyright @ 2016 by authors and Scientific Research Publishing Inc.

This work is licensed under the Creative Commons Attribution International License (CC BY). http://creativecommons.org/licenses/by/4.0/

C. (i) Open Access

\begin{abstract}
Background: Whilst relatively new in physiotherapy, simulation has been used in various medical and nursing programs to develop manual and communication skills and clinical reasoning. The primary aim of this study was to develop and introduce simulation activities into the physiotherapy curricula at an Australian University and evaluate students' motivation to learn. The secondary aim was to evaluate differences in perceived value between first and second year students. Methods: During 2014, first and second year physiotherapy students at Curtin University, Western Australia enrolled in three units had the opportunity to participate in newly developed simulated scenarios as part of their program. On completion of these novel learning activities, students were invited to undertake the Instructional Materials Motivation Scale (IMMS) questionnaire. Results: Total IMMS scores for the three units $(147,137$ and 156) indicated that overall, students found the simulation based learning activities motivating. First year students found that simulation gained their attention and was more enjoyable than second year students. Conclusions: As motivation entices people to learn and to complete activities, there may be great potential for improved learning outcomes using this modality in physiotherapy curricula, especially in the first year of the program.
\end{abstract}

\section{Keywords}

Simulation, Simulation Based Learning, Physiotherapy

\section{Introduction}

The demand for an increase in the number of trained health professionals while maintaining a sound educational standard continues to challenge health educators. Limited clinical placements affect and dilute real clinical ex-

${ }^{*}$ Corresponding author.

How to cite this paper: Dennis, D. M., Sainsbury, D. A., Redwood, T. M., Ng, L., \& Furness, A. (2016). Introducing Simulation Based Learning Activities to Physiotherapy Course Curricula. Creative Education, 7, 878-885.

http://dx.doi.org/10.4236/ce.2016.76092 
periences (Yuan, Williams, Fang, \& Ye, 2012) and result in fewer opportunities to learn the skills required, less supervision (Keller, 1979; Maran \& Glavin, 2003), a reduction in clinical learning experiences and consequently clinical competence (Murray et al., 2007). Simulation based learning (SBL) consists of both a "hands-on" experience of a mock-clinical event or situation and a debrief session of reflection and feedback (Shinnick, Woo, \& Mentes, 2011). Whilst relatively new in physiotherapy curricula and with few publications (Mori, Carnahan, \& Herold, 2015; Ohtake, Lazarus, Schillo, \& Rosen, 2013; Smith, Prybylo, \& Conner-Kerr, 2012), human patient simulation (HPS) is used in many countries across various medical (Barsuk, Cohen, Feinglass, McGaghie, \& Wayne, 2009; Evans et al., 2010; Issenberg, McGaghie, Petrusa, Lee Gordon, \& Scalese, 2005; Morgan, Cleave-Hogg, McIlroy, \& Devitt, 2002; Steadman et al., 2006; Zendejas, Wang, Brydges, Hamstra, \& Cook, 2013) and nursing programs (Ballangrud, Hall Lord, Hedelin, \& Persenius, 2013; Davis, Kimble, \& Gunby, 2014; Garrett, MacPhee, \& Jackson, 2010; Ironside, Jeffries, \& Martin, 2009; Johannesson, Silén, Kvist, \& Hult, 2013; Shinnick et al., 2011; Traynor, Gallagher, Martin, \& Smyth, 2010), with various measures of outcome. These activities provide students with opportunities to perform treatment on a realistic patient (rather than a peer) in an environment similar to that they will experience in actual clinical practice. Students may therefore develop skills in clinical reasoning, diagnosing, communication, and managing patients with health issues, thereby meeting learning outcomes across curricula. It has been demonstrated that SBL is better than problem based learning (Steadman et al., 2006) or traditional learning approaches (Garrett et al., 2010) for acquisition of clinical skills. The SBL activity also gives students practice at giving and receiving personalized feedback which are important skills for the reflective practitioner (Ellaway, Poulton, Fors, McGee, \& Albright, 2008).

Evidence suggests that it is important to introduce SBL to students early in the curriculum so that they become more comfortable with the learning modality, and are able to undergo more complex scenarios later in their training (Henneman \& Cunningham, 2005). Simulation learning activities may also be used to develop appropriate clinical experiences throughout the curricula so that students can apply the knowledge they have gained at that point in the curricula to meaningful clinical experiences. This not only improves student engagement with the material being learnt but also allows students the opportunity to learn without the fear of harming the patient (Bond \& Spillane, 2002; McLaughlin, Doezema, \& Sklar, 2002; Morgan et al., 2002) and with repetitive practice.

In the evaluation of simulation experiences, student factors that may influence student achievement have been identified as needing further investigation (Ironside et al., 2009). As we develop SBL experiences for physiotherapy students, it is important that we assess the self-efficacy experiences of students. The primary aim of this study was to develop and introduce three SBL activities into the physiotherapy curricula at an Australian University and evaluate students' motivation to learn. The secondary aim was to see if there was a difference in perceived value between first and second year physiotherapy students.

\section{Methods}

\subsection{Study Design}

A descriptive cross-sectional design was used to identify students' motivation to learn utilizing SBL activities in the physiotherapy curricula.

\subsection{Participants}

During 2014, physiotherapy students at Curtin University, Western Australia enrolled in a first year patient handling unit (PT1), a second year musculoskeletal unit (PT2a) and a second year gait analysis unit (PT2b) had the opportunity to participate in physiotherapy SBL scenarios with actors who assumed the roles of various patients according to individualized scripts.

This research was approved by Curtin University Ethics Committee (Approval Number PT010/2014). The information and informed consent documents were posted online at the beginning of the questionnaire, and completion of the survey implied student consent.

\subsection{Scenario Development}

The novel physiotherapy SBL activities were designed by the authors in conjunction with the unit coordinators to address core topics in a standardized, structured and safe learning environment. Information including the ob- 
jectives of the lesson, preparatory activities, and an outline of the learning activities were detailed in the unit information folder on the electronic learning management system for each unit, accessible to students, and the SBL activities were incorporated into practical classes.

\subsection{Scenarios}

1) PT1: A hospital patient with a musculoskeletal problem to be mobilized out of bed for the first time

2) PT2a: An outpatient with heel pain to be educated regarding the pathology of the complaint, and taught some exercises

3) PT2b: An outpatient with a limp to be assessed for primary gait impairment

\subsection{Outcome Measure}

The students' perceptions of the SBL were evaluated using the Instructional Materials Motivation Scale (IMMS) questionnaire (Keller, 1979, 1987, 2010). This instrument may be used to measure how motivated students are regarding specific situations including lessons, courses or instructional method. It was designed to measure attitudes regarding specific situations, and has established validity and reliability (Keller, 1987, 2010) over four subscales, attention, relevance, confidence and satisfaction (ARCS).

There are 36 statements in this questionnaire, with a choice of five responses $(1=$ not true, $2=$ slightly true, $3=$ moderately true, $4=$ mostly true and $5=$ very true). Participants were asked to think about each statement in relation to the SBL activity and to indicate their response. The survey is scored for each subscale as well as the total score. Whereas the minimum/mid-point/maximum total scores are 36/180/108 respectively, each subscale has variable minimum/maximum/midpoints according to the variable number of items contributing to the score.

\subsection{Process}

After completing any of the physiotherapy SBL activities, including facilitated debriefing, students were invited to undertake the IMMS survey which was generated using the Qualtrics survey tool (Qualtrics software. Provo, UT: Qualtrics Research Suite) and delivered via email link. Participating in the study was not a requirement for successful completion of the unit and data collected were unidentifiable.

\subsection{Statistics}

Summary statistics including means, standard deviations, and ranges are provided for all subscales. Kruskal Wallis ANOVA was used to investigate whether the mid scores for each subscale differed between the three units (with significance set at $\alpha=0.05$ ). Mann-Whitney $U$ tests were then used to locate the source of significance using a series of pairwise comparisons (with significance at the Bonferroni corrected $\alpha=0.016$ ). All analyses were conducted using IBM SPSS Statistics for Windows, Version 22.0. Armonk, NY: IBM Corp. (Released 2013).

\section{Results}

\subsection{Student Participation}

The number of students who participated in the SBL activities is shown in Table 1. Of those who participated, there was a survey response rate between $13.8 \%$ and $42.6 \%$ for the IMMS.

\subsection{Students' Perceptions of Their Value of the SBL Activities}

Total IMMS scores were 147, 137 and 156 for PT2a, PT2b and PT1 respectively (Figure 1). The descriptive statistics for each subscale across all units are shown in Table 2. The PT1 unit had mean scores of 4 and above for each subscale. The PT2a unit had mean scores of 4 and above for 3 of the subscales (attention, relevance and confidence) and the PT2b unit had a mean score above 4 for the relevance subscale only. Within each of the 3 units, mean scores for attention and relevance subscales were highest.

The first year unit PT1 scored highest for the attention subscale (mean of 4 and above for 8 of the 12 items, 
Table 1. Participant flow.

\begin{tabular}{cccc}
\hline & $\begin{array}{c}\text { PT2a, } \\
\text { Student enrolment } \\
\mathrm{n}=205\end{array}$ & $\begin{array}{c}\text { PT2b, } \\
\text { Student enrolment } \\
\mathrm{n}=181\end{array}$ & $\begin{array}{c}\text { PT1, } \\
\text { Student enrolment } \\
\mathrm{n}=192\end{array}$ \\
\hline $\begin{array}{c}\text { Students participating SBL, } \\
\mathrm{n}(\% \text { of those enrolled in unit) } \\
\begin{array}{c}\text { Students completing IMMS, } \\
\mathrm{n}(\% \text { of those undertaking SBL) }\end{array}\end{array}$ & $173(84)$ & $145(80)$ & $115(59.9)$ \\
\hline
\end{tabular}

Table 2. Descriptive statistics for each unit across all subscales: mean score (SD).

\begin{tabular}{cccc}
\hline Scales & PT2a, $\mathrm{n}=41$ & PT2b, $\mathrm{n}=20$ & PT1, $\mathrm{n}=49$ \\
\hline Attention & $4.1(0.5)$ & $3.9(0.6)$ & $4.3(0.3)$ \\
Relevance & $4.3(0.5)$ & $4.1(0.7)$ & $4.5(0.3)$ \\
Confidence & $4.0(0.6)$ & $3.7(0.6)$ & $4.2(0.3)$ \\
Satisfaction & $3.9(0.7)$ & $3.5(0.9)$ & $4.3(0.5)$ \\
\hline
\end{tabular}

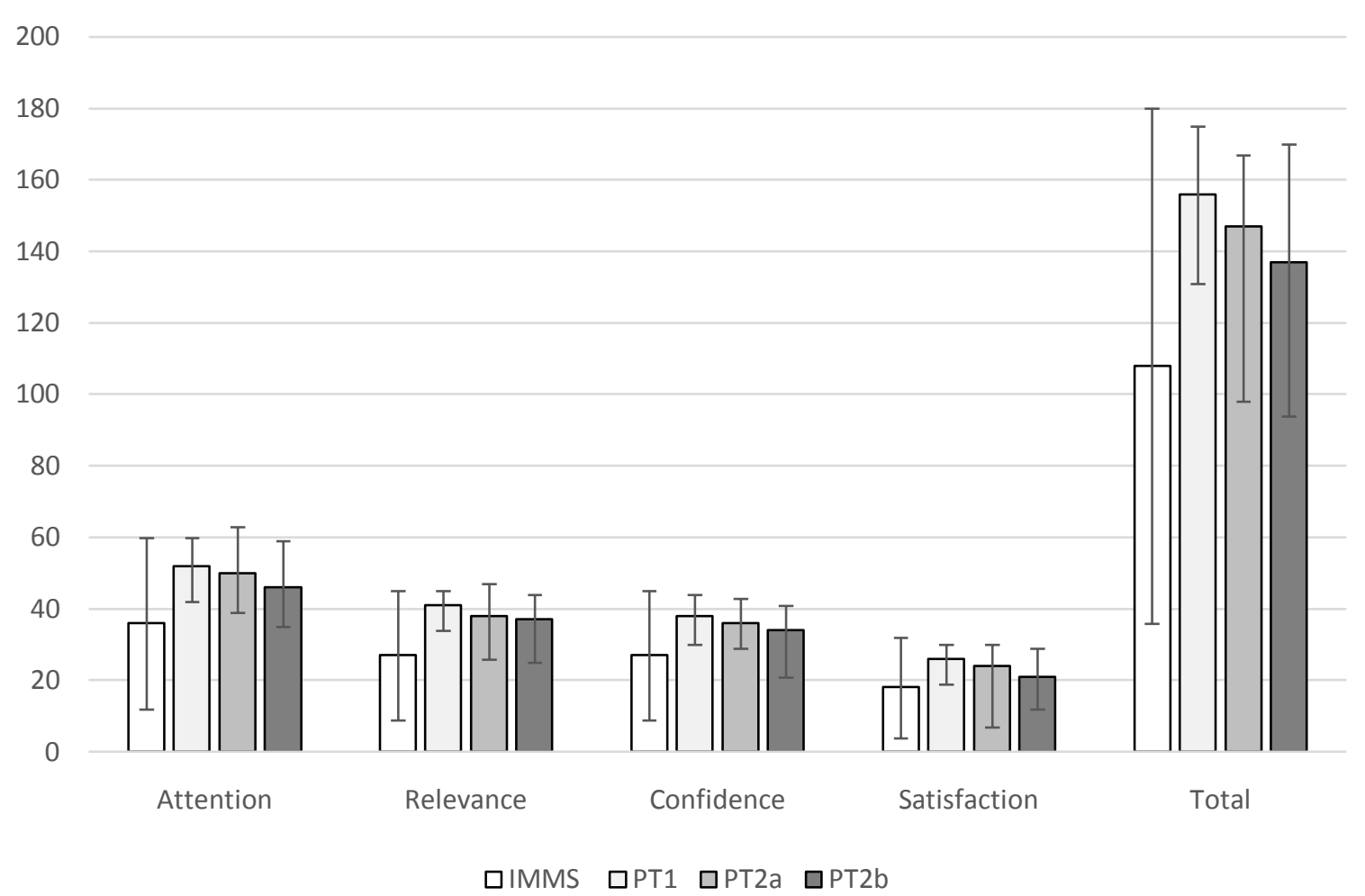

Figure 1. Comparative median and range of subscale scores of the Instructional Materials Motivation Scale (IMMS) and each of the simulation based learning (SBL) activities.

compared to PT2a (7) and PT2b (5); the relevance subscale (mean of 4 and above for 9 of the 10 sub items, compared to PT2a (7) and PT2b (6) and the satisfaction subscale (mean of 4 or above for all of the 6 items, compared to PT2a (3) and PT2b (0). The confidence subscale scored the lowest across all units.

\subsection{Perception of Value of SBL between First and Second Year Physiotherapy Students}

There was a statistically significant difference between the units across the scores for all of the subscales (Table 3). Post-hoc Mann-Whitney U tests were undertaken to locate the source of the difference with statistical 
Table 3. Statistics of units across subscales ${ }^{*}$.

\begin{tabular}{cccccc}
\hline & $\begin{array}{c}\text { Mean rank PT2a } \\
\mathrm{N}=41\end{array}$ & $\begin{array}{c}\text { Mean rank PT2b } \\
\mathrm{N}=20\end{array}$ & $\begin{array}{c}\text { Mean rank PT1 } \\
\mathrm{N}=49\end{array}$ & H(2df) value & $p$-value \\
\hline Attention & 51 & 40 & 66 & 11.0 & 0.004 \\
Relevance & 48 & 45 & 66 & 9.9 & 0.007 \\
Confidence & 55 & 37 & 63 & 10.0 & 0.007 \\
Satisfaction & 51 & 36 & 68 & 15.7 & $<0.001$ \\
\hline
\end{tabular}

${ }^{*} p$ value derived from Kruskal Walllis ANOVA.

significance set at the Bonferroni corrected alpha of 0.016. Results showed significant differences between PT1 and PT2a for relevance $(p=0.005)$ and satisfaction $p=0.007)$ and between PT1 and PT2b for all subscales attention $(p=0.004)$, relevance $(0.024)$, confidence $(p=0.001)$ and satisfaction $(p<0.001)$. The only significant difference found between PT2a and PT2b was in the satisfaction scale $(p=0.048)$. This suggested that first year students found the SBL activity gained their attention and was more enjoyable than second year students.

\section{Discussion}

High mean overall scores across all units indicate that physiotherapy students felt motivated during the SBL scenarios. As motivation entices people to learn and complete activities, there is great potential for improved learning outcomes using this modality in this group. If students are enthusiastic and confident with an instructional tool it has potential to enhance learning through increased motivation and effort (Laschinger et al., 2008) thereby improving competence (Gordon, Wilkerson, Shaffer, \& Armstrong, 2001).

The level of motivation may have developed for a number of reasons. The SBL was completely novel to all students regardless of whether they had experienced the physiotherapy curricula before (second year students) or not (first years). Results suggest that over all units the SBL maintained the students' attention and it may have been this novelty that did so, thereby facilitating their learning. This was particularly evident from the scoring of items related to clarity of the lesson (it was not abstract), the novel presentation of the lesson (it was not dry or boring), and the fact that the task was not overwhelming (there was not too much information presented).

Relatively speaking, results suggest that the first year students found the SBL to gain their attention and be more enjoyable than the second year students. It may be that their lack of clinical exposure impacted positively in gaining their attention and promoting their enjoyment. In terms of the second year students, the PT2b SBL activity was perceived to be the least enjoyable. The objective of this SBL was to provide students with a chance to practice what they had learnt on each other on a simulated "patient" and there may have been a mismatch in that the student's had an expectation that they would be able to achieve a high standard of skill during the SBL activity. This disparity may have resulted in reduced enjoyment when participating in the lesson.

"Relevance" scored highly across all units, and this may be due to the fact that in the early years of the curricula, physiotherapy students have limited opportunity to translate theory into practice in "real" scenarios involving "real" patients. Our SBL activities provided a new bridge to clinical practice that role-playing with their peers may not have provided previously. This corresponded to high IMMS scores in how the SBL task related to things they knew, demonstrated the importance of things they did and did not know, and showed the things that were useful. Interaction with any patient that did not resemble their peers was not only novel, but relevant. In PT1 in particular, the SBL activity was designed to replicate an upcoming exam setup, and thereby provided safe practice without the expectation of passing or failing. The SBL allowed students to gain practical experience and test themselves.

All but one item of the confidence subscale scored above 3, representing a high rate of confidence from students relating to the SBL activities and content. Interestingly, confidence scores relating to preparation items ("when I first looked at the lesson" and "after reading the introduction information") scored lowest. This may reflect the newness of the learning modality, and should reinforce the importance of adequate pre briefing whereby under preparedness of students may compromise the potential of a learning experience.

Whilst interpretation of the data pertaining to satisfaction looks variable across the items, all mean scores were above 3, representing good overall satisfaction with the SBL. Differences are more obvious when comparing results across units, with PT2b being the source of least satisfaction and PT1 leaving students the most satis- 
fied. This may relate to an order effect (perhaps students had different expectations coming into PT2b having completed PT2a) or may perhaps relate to differences in debrief design across units, whereby the nature of the patient problem was less clear in PT2b compared to the other 2 activities.

Previous studies have evaluated the impact of HPS on physiotherapy students' confidence (Ohtake et al., 2013; Smith et al., 2012), and satisfaction (Smith et al., 2012) in a cardiopulmonary setting, and found it to be an effective education tool. This study has demonstrated that students are motivated to participate in HPS in a variety of physiotherapy settings, and at an early stage of their education. There have been various frameworks suggested in the literature for the development of simulations (Garrett et al., 2010; Henneman \& Cunningham, 2005; Jeffries, 2015). Ours considered the fact that although experiences needed to be similar in meeting learning goals, they also had to be unique in order to engage the students from one unit to another. We developed a variety of setups to keep the activities interesting and fresh, and we designated specific and variable roles within the student groups. We also designed detailed guidelines relating to the expectations of students during each debriefing session.

A strength of the study was that no students had undertaken SBL prior to 2014. The cohorts were therefore equivalent in terms of exposure to the teaching modality. A limitation of the study was that the students each had different roles within the scenarios and the nature of their role may have influenced their motivation and satisfaction with the activity. Another limitation was the relatively small number of survey responders from the cohort who actively participated in each activity. Care should therefore be taken in generalizing survey results to the whole student population, however the trends demonstrated support the value of pursuing future development of the modality in physiotherapy curricula.

While other disciplines have explored the student experience in terms of what the most important components of the SBL activity from their perspective (Kelly, Hager, \& Gallagher, 2014), it was beyond the scope of this preliminary study to explore further the components of simulation deemed most valuable to the physiotherapy student. Further work in this area will be valuable in the design of future scenarios. Likewise the impact of SBL activities on student's success in other coursework may be positive and needs further investigation.

\section{Conclusion}

This study has demonstrated that first and second year physiotherapy students are able to be engaged in SBL activities. Further, we have demonstrated that it is possible to simulate basic clinical scenarios in the early years of training in order to provide a safe environment for the practice of physiotherapy clinical skills in the assessment and treatment of the simulated patients undertaking these scenarios.

\section{Acknowledgements}

The authors would like to thank all of the Curtin University students who participated in the simulation based learning activities and completed outcome surveys.

\section{Declaration of Interest}

The authors report no declarations of interest. This work was supported by the Teaching Excellence Development Fund from Curtin University [Grant number 63].

\section{References}

Ballangrud, R., Hall Lord, M., Hedelin, B., \& Persenius, M. (2013). Intensive Care Unit Nurses’ Evaluation of Simulation Used for Team Training. Nursing in Critical Care, 19, 175-184. http://dx.doi.org/10.1111/nicc.12031

Barsuk, J., Cohen, E., Feinglass, J., McGaghie, W., \& Wayne, D. (2009). Use of Simulation-Based Education to Reduce Catheter-Related Bloodstream Infections. Archives of Internal Medicine, 169, 1420-1423. http://dx.doi.org/10.1001/archinternmed.2009.215

Bond, W. F., \& Spillane, L. (2002). The Use of Simulation for Emergency Medicine Resident Assessment. Academic Emergency Medicine, 9, 1295-1299. http://dx.doi.org/10.1197/aemj.9.11.1295

Davis, A., Kimble, L., \& Gunby, S. (2014). Nursing Faculty Use of High-Fidelity Human Patient Simulation in Undergraduate Nursing Education: A Mixed-Methods Study. The Journal of Nursing Education, 53, 142-150.

http://dx.doi.org/10.3928/01484834-20140219-02 
Ellaway, R., Poulton, T., Fors, U., McGee, J. B., \& Albright, S. (2008). Building a Virtual Patient Commons. Medical Teacher, 30, 170-174. http://dx.doi.org/10.1080/01421590701874074

Evans, L.V., Dodge, K.L., Shah, T.D., et al. (2010). Simulation Training in Central Venous Catheter Insertion: Improved Performance in Clinical Practice. Academic Medicine, 85, 1462-1469. http://dx.doi.org/10.1097/ACM.0b013e3181eac9a3

Garrett, B., MacPhee, M., \& Jackson, C. (2010). High-Fidelity Patient Simulation: Considerations for Effective Learning. Nursing Education Perspectives, 31, 309-313.

Gordon, J., Wilkerson, W., Shaffer, D., \& Armstrong, E. (2001). “Practicing” Medicine Without Risk: Students’ and Educators’ Responses to High-Fidelity Patient Simulation. Academic Medicine, 76, 469-472. http://dx.doi.org/10.1097/00001888-200105000-00019

Henneman, E., \& Cunningham, H. (2005). Using Clinical Simulation to Teach Patient Safety in an Acute/Critical Care Nursing Course. Nurse Educator, 30, 172-177. http://dx.doi.org/10.1097/00006223-200507000-00010

Ironside, P. M., Jeffries, P. R., \& Martin, A. (2009). Fostering Patient Safety Competencies Using Multiple-Patient Simulation Experiences. Nursing Outlook, 57, 332-337. http://dx.doi.org/10.1016/j.outlook.2009.07.010

Issenberg, S. B., McGaghie, W., Petrusa, E., Lee Gordon, D., \& Scalese, R. (2005). Features and Uses of High-Fidelity Medical Simulations That Lead to Effective Learning: A BEME Systematic Review. Medical Teacher, 27, 10-28. http://dx.doi.org/10.1080/01421590500046924

Jeffries, P. A. (2015). Framework for Designing, Implementing, and Evaluating Simulations Used as Teaching Strategies in Nursing. Nursing Education Perspectives, 26, 96-103.

Johannesson, E., Silén, C., Kvist, J., \& Hult, H. (2013). Students’ Experiences of Learning Manual Clinical Skills through Simulation. Advances in Health Sciences Education, 18, 99-114. http://dx.doi.org/10.1007/s10459-012-9358-z

Keller, J. M. (1979). Motivation and Instructional Design: A Theoretical Perspective. Journal of Instructional Development, 2, 26-34. http://dx.doi.org/10.1007/BF02904345

Keller, J. M. (1987). Development and Use of the ARCS Model of Instructional Design. Journal of Instructional Development, 10, 2-10. http://dx.doi.org/10.1007/BF02905780

Keller, J. M. (2010). Tools to Support Motivational Design. In J. M. Keller, Motivational Design for Learning and Performance: The ARCS Model Approach (pp. 267-295). Boston, MA: Springer US. http://dx.doi.org/10.1007/978-1-4419-1250-3_11

Kelly, M., Hager, P., \& Gallagher, R. (2014). What Matters Most? Students’ Rankings of Simulation Components That Contribute to Clinical Judgment. The Journal of Nursing Education, 53, 97-101. http://dx.doi.org/10.3928/01484834-20140122-08

Laschinger, S., Medves, J., Pulling, C., McGraw, D. R., Waytuck, B., Harrison, M. B., \& Gambeta, K. (2008). Effectiveness of Simulation on Health Profession Students' Knowledge, Skills, Confidence and Satisfaction. International Journal of Evidence-Based Healthcare, 6, 278-302. http://dx.doi.org/10.1111/j.1744-1609.2008.00108.x

Maran, N. J., \& Glavin, R. J. (2003). Low- to High-Fidelity Simulation-A Continuum of Medical Education? Medical Education, 37, 22-28. http://dx.doi.org/10.1046/j.1365-2923.37.s1.9.x

McLaughlin, S. A., Doezema, D., \& Sklar, D. P. (2002). Human Simulation in Emergency Medicine Training: A Model Curriculum. Academic Emergency Medicine, 9, 1310-1318.

Morgan, P. J., Cleave-Hogg, D., McIlroy, J., \& Devitt, J. H. (2002). Simulation Technology: A Comparison of Experiential and Visual Learning for Undergraduate Medical Students. Anesthesiology, 96, 10-16. http://dx.doi.org/10.1097/00000542-200201000-00008

Mori, B., Carnahan, H., \& Herold, J. (2015). Use of Simulation Learning Experiences in Physical Therapy Entry-to-Practice Curricula: A Systematic Review. Physiotherapy Canada, 67, 194-202. http://dx.doi.org/10.3138/ptc.2014-40E

Murray, D. J., Boulet, J. R., Avidan, M., Kras, J. F., Henrichs, B., Woodhouse, J., \& Evers, A. S. (2007). Performance of Residents and Anesthesiologists in a Simulation-Based Skill Assessment. Anesthesiology, 107, 705-713. http://dx.doi.org/10.1097/01.anes.0000286926.01083.9d

Ohtake, P., Lazarus, M., Schillo, R., \& Rosen, M. (2013). Simulation Experience Enhances Physical Therapist Student Confidence in Managing a Patient in the Critical Care Environment. Physical Therapy, 93, 216-228. http://dx.doi.org/10.2522/ptj.20110463

Shinnick, M., Woo, M., \& Mentes, J. (2011). Human Patient Simulation: State of the Science in Prelicensure Nursing Education. The Journal of Nursing Education, 50, 65-72. http://dx.doi.org/10.3928/01484834-20101230-01

Smith, N., Prybylo, S., \& Conner-Kerr, T. (2012). Using Simulation and Patient Role Play to Teach Electrocardiographic Rhythms to Physical Therapy Students. Cardiopulmonary Physical Therapy Journal, 23, 36-42.

Steadman, R., Coates, W., Huang, Y., Matevosian, R., Larmon, B., McCullough, L., \& Ariel, D. (2006). Simulation-Based Training Is Superior to Problem-Based Learning for the Acquisition of Critical Assessment and Management Skills. Crit- 
ical Care Medicine, 34, 151-157. http://dx.doi.org/10.1097/01.CCM.0000190619.42013.94

Traynor, M., Gallagher, A., Martin, L., \& Smyth, S. (2010). From Novice to Expert: Using Simulators to Enhance Practical Skill. British Journal of Nursing, 19, 1422-1426. http://dx.doi.org/10.12968/bjon.2010.19.22.1422

Yuan, H. B., Williams, B. A., Fang, J. B., \& Ye, Q. H. (2012). A Systematic Review of Selected Evidence on Improving Knowledge and Skills through High-Fidelity Simulation. Nurse Education Today, 32, 294-298. http://dx.doi.org/10.1016/j.nedt.2011.07.010

Zendejas, B., Wang, A., Brydges, R., Hamstra, S., \& Cook, D. (2013). Cost: The Missing Outcome in Simulation-Based Medical Education Research: A Systematic Review. Surgery, 153, 160-176. http://dx.doi.org/10.1016/j.surg.2012.06.025 